\title{
HBIM WORK METHODOLOGY APPLIED TO PREVENTIVE MAINTENANCE: A STATE-OF-THE-ART REVIEW
}

\author{
JORGE GARCÍA-VALLDECABRES ${ }^{1}$, ANTONIO GALIANO-GARRIGÓS ${ }^{2}$, \\ LUIS CORTES MESEGUER ${ }^{3} \&$ MARIA CONCEPCIÓN LÓPEZ GONZÁLEZ ${ }^{1}$ \\ ${ }^{1}$ Department of Architectural Graphic Expression, Universitat Politècnica València, Spain \\ ${ }^{2}$ Department of Architectural Constructions, University of Alicante, Spain \\ ${ }^{3}$ Department of Architectural Constructions, Universitat Politècnica València, Spain
}

\begin{abstract}
The consolidation of BIM work environments and the efficient management of construction information are reaching previously forgotten facets of the buildings' life cycle. Preventive conservation and maintenance, which affect the building operation that accounts for $80 \%$ of $\mathrm{CO}_{2}$ emissions, are being subject to an improvement in their procedures based on the digitization of information. These actions are reaching historical buildings where procedures are not only being developed to improve their maintenance, but also in areas such as historical documentation and cultural management. The generation of repositories with documentation of the buildings is making it possible to establish new relationships with society, improving the conservation of buildings and designing actions that avoid future risks. There are different types of maintenance: corrective, preventive and predictive and despite its advantages, the agents in charge of these buildings do not always perform it properly. Furthermore, dysfunctions and lack of coordination are detected as many agents act without having adequate information. To solve these problems, BIM work environments are positioned as a valid alternative since they provide a centralized and updated repository where the information is arranged so that it is available to the different agents when they need it. This information can be historical or technical, including digital models and evaluation of deterioration and intervention processes. The objective of this research is the development of an analysis of the degree of implementation of BIM strategies applied to preventive maintenance in historic buildings and the analysis of the investigations carried out. This work is part of the first results of the research project entitled "Analysis and Development of the integration of BHIM in GIS for the creation of a tourist planning protocol of the cultural heritage of a destination (HBIMSIG-TOURISM)" granted by the Ministry of Research of Spain under the 2020 call for R\&D\&I Projects oriented to the Challenges of the Society with the reference PID2020-119088RB-I00.
\end{abstract}

Keywords: preventive conservation, management, BIM, HBIM, heritage.

\section{INTRODUCTION}

The protection and conservation of cultural heritage has been established as one of the necessary actions to be developed by modern societies in the process to define a feeling of belonging [1]. Historical buildings, as elements of an urban fabric, are part of a mental map that people develop which allows them to orient themselves in the city and in the circuits that it has [2]. For that matter, the cultural activity in which heritage participates becomes part of the cultural structure of the city and helps to put it in value by improving the relationship between the physical environment and the human perception of spaces [3]. Moreover, historical heritage helps the balance between the activities that occur in public spaces by being able to generate poles of attraction based on the people who are attracted by the interest that the building generates. In many cases, these buildings contribute to generating a balance in the activities that take place in the urban fabric, demonstrating the quality that it has [4].

However, to have a building considered historical heritage participate in the city activity, it must be kept in an ideal state of maintenance, allowing it to develop the use for which it was designed or to have the necessary modifications to adapt to a new one. The Athens 
Charter of 1931 also states that there is no better tool for the conservation of heritage than affection and respect by people, in addition to recommending assigning useful uses for these buildings. More recently, in the 2000 Krakow Charter, the spirit of the Venice Charter is ratified and its first two objectives specify and highlight the importance of heritage maintenance as an elemental part of the process of preserving a property. The National Plans for the conservation of heritage usually recommend improving the training and information of the stakeholders participating in the process of exploitation and conservation of this type of buildings. At the same time, it is needed the improvement of the information available to potential visitors interested in knowing the characteristics of the historical heritage at different levels.

Developing preventive conservation plans (CP) is often considered a sign of maturity in a sustainable process of managing cultural heritage. The CP could be defined as a set of actions that aims to preserve heritage by ensuring its accessibility by future generations. The $\mathrm{CP}$ also defines actions which allow to perpetuate the useful life of this type of buildings in optimal conditions, as well as designing conservation-restoration actions and defining rules to allow them to be enjoyed by interested citizens without causing deterioration [5]. These PC plans must be flexible and sequential, enabling a strategy that requires a schedule with short, medium and long-term objectives [6]. In this sense, the National Preventive Conservation Plan in Spain [7] has been developed with the objective of developing research actions to identify and analyze risks, conservation methods and techniques. It must also identify criteria and work methods, coordination of the actions, the optimization of the resources and the way to access information, as well as the revision of collections and funds [8] (Fig. 1).

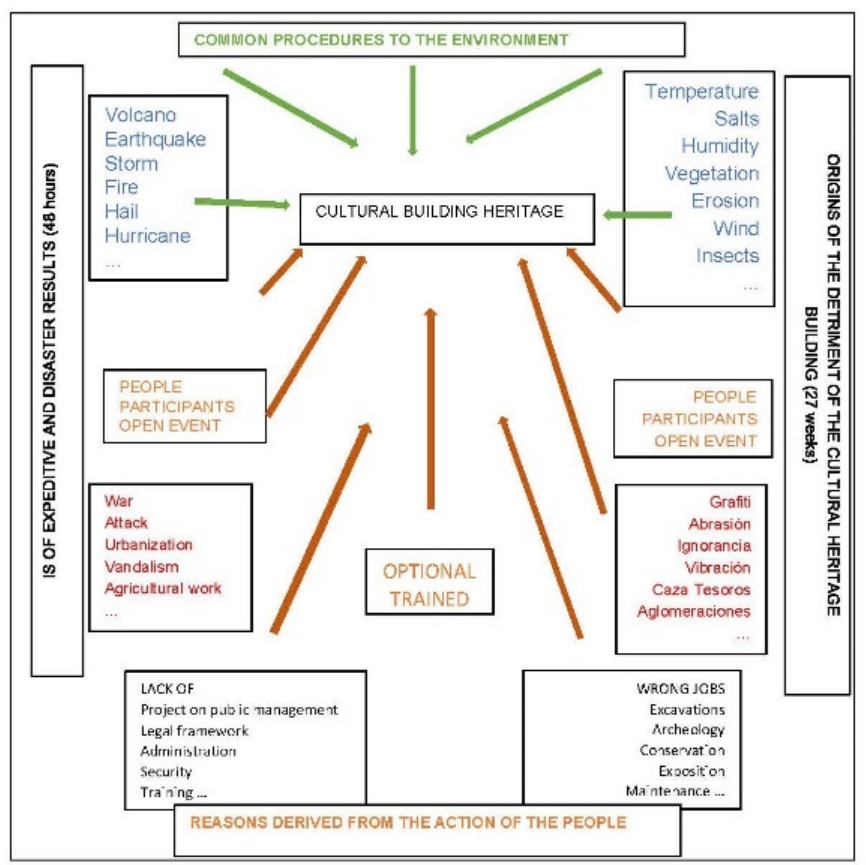

Figure 1: Causes of deterioration of cultural property. (Source: Own interpretation of painting by Guichen [5].) 
Maintaining cultural heritage in adequate conditions allows improving its presence at the level of society and its inclusion in cultural circuits, generating conservation conflicts due to an excessive influx of visitors, even causing deterioration (Fig. 2). For this reason, it is necessary to include visitor management in preventive conservation plans and develop an adequate management of visits [9].

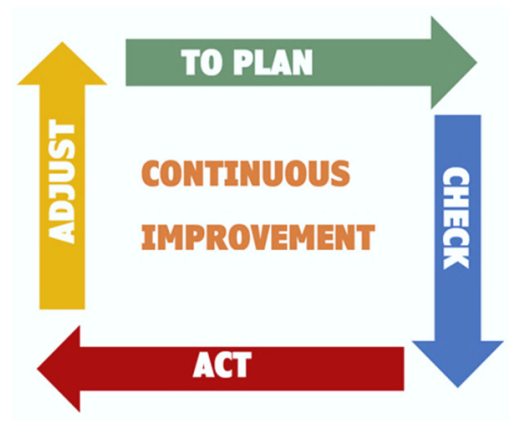

Figure 2: Application cycle of the PDCA Systematics or Deming circle. (Source: Own interpretation of the CP National Plan [7].)

The CP's objective is to maintain the necessary conditions to preserve heritage in use. These conditions are lost when maintenance tasks or planned restoration processes are abandoned, and deterioration may appear. It can be assured that deterioration processes are normally produced by interlocking factors that affect the enclosure or the structure of the building. Sometimes they have their origin in a lack of adaptation to improve its functionality. That is why a CP plan must define research objectives to identify risks, work methods and interventions, coordinate actions, optimize resources and provide a centralized and updated repository with the heritage available information. In any case, this process must begin with a complete survey with the most advanced digital tools [10].

In addition, a structured analysis of the available information can allow the development of diagnoses based on the data collected in different periods of the history of the building [11]. However, the simulation of these historical phases becomes a complex process due to the low level of detail of the information that can be managed and visualized through digital CAD representations [10].

Moreover, the implementation of building information modeling (BIM) methodologies in the construction sector is a significant improvement in the management of construction information. BIM pursues the generation of a centralized repository of construction information accessible to the different stakeholders and available during the building life.

The possibilities that BIM is offering for the management of building information is being extended to historical heritage through HBIM (heritage building information modeling). This discipline is offering the possibility of creating centralized repositories in which not only architectural information is managed. All the actions that have been carried out over the years on a building may be completed with information related to the management of visitors and preventive maintenance. A BIM model, reinforced by the detailed information it contains, is an excellent tool for monitoring and evaluating the performance, operation and deterioration of heritage buildings, collecting and classifying various data that can coexist in a dynamic model that can be updated over time. 
The use of new information technologies is also making it possible to carry out simulations on the future buildings performance, supporting the decision-making process and analyzing future results that may affect the building life cycle [12]. These simulations can be considered in the heritage maintenance process and may be part of the CP plans (Fig. 3).

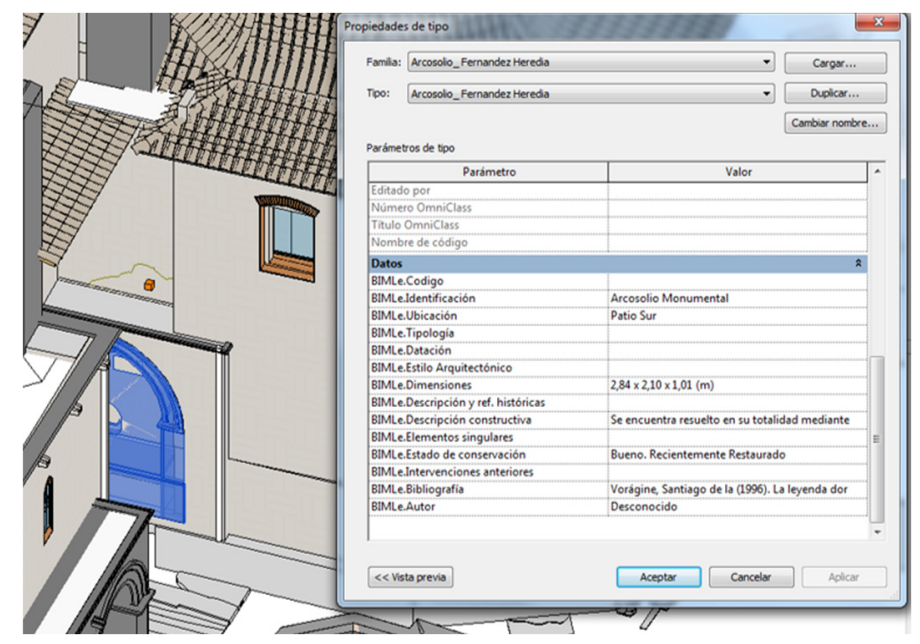

Figure 3: Partial view screen capture and H-BIM Revit model arch-burial properties box.

However, it is considered that the implementation of new technologies that belong to the HBIM environment applied to the Preventive Conservation of buildings is in an incipient state. It is still needed more scientific literature that allows supporting the development of new conservation plans based on previous experiences from other researchers.

\section{OBJECTIVE AND METHODOLOGY}

The objective of this research is to carry out a systematic review of the existing literature that relates the use of any type of HBIM strategies with preventive conservation plans applied to heritage. To carry out this research, a methodology has been designed that begins with the search for research examples about the above-mentioned themes. It has also been included in the search synergies among HBIM and building rehabilitation, life cycle, heritage information management and preventive conservation. During the search databases such as Web of Science, Scopus and Google Scholar were used. Keywords used during the search of articles included HBIM, LCA, conservative maintenance, building restoration, and preventive conservation.

The contributions found have been organized according to their affinity to one of these groups: HBIM and building restoration, HBIM and life cycle analysis, HBIM and heritage information management, and finally HBIM and preventive conservation. Once the different contributions have been analyzed in a systematic way, research strategies are extracted to finish with a discussion of the results and the conclusions.

\section{ANALYSIS OF AVAILABLE BIBLIOGRAPHY}

As it was previously mentioned, a systematic search is carried out focused on research that considers the preventive conservation of buildings and the use of new technologies in the HBIM environment. The contributions found have been divided into four groups in which 
the use of HBIM acts as a common element and is related to three areas present in preventive conservation such as building restoration, information management and life cycle analysis. Finally, the analysis of contributions focused on the development of HBIM with preventive conservation plans is carried out (Fig. 4).

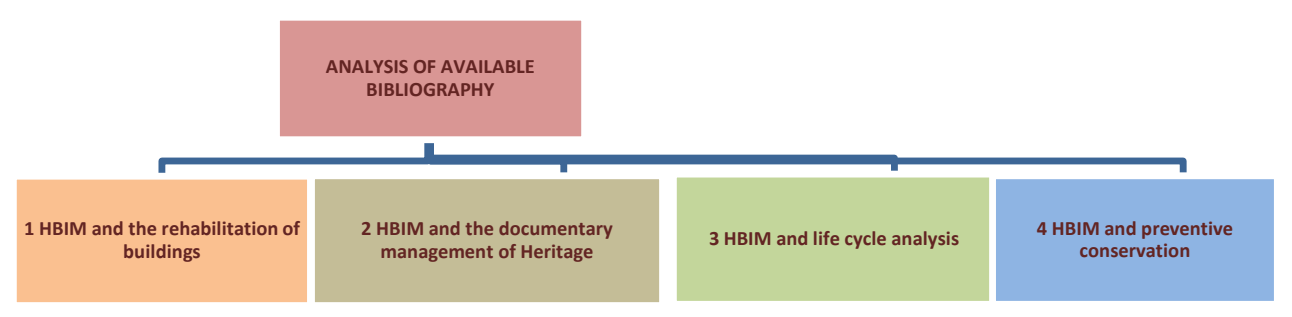

Figure 4: Outline of the search results.

\subsection{HBIM and the buildings restoration}

The implementation of HBIM in building restoration processes is carried out through case studies in many of the research examples analyzed. The absence of general guidelines makes researchers show their findings through applied research. In the Heritage Building Information Modelling book [13] the authors confirm the lack of prototypes focused on Heritage-BIM that can be used to contrast the experiences acquired and the lack of dissemination of the case studies carried out. In addition, it is worth noting the lack of research that allows distinguishing the particularities between BIM and HBIM, concluding the need for research in this area.

A special focus must be done over the interventions carried out for the restoration of buildings that try to generate synergies between different disciplines though the information management platforms of the BIM environment but adapted to the particularities of heritage buildings, such as the case of the rehabilitation of the Basilica of Collemaggio in L'Aquila (Italy) [14], [15].

It is possible to find contributions that define intervention strategies on listed buildings under restoration processes in which, based on 3D representations, it is possible to establish the interoperability of the information between the different disciplines involved on the construction process [16].

Technologies of HBIM environment have also been used to assess the historical values of buildings, such as the Cathedral of Cristo Rey in the city of Huejutla de Reyes, Hidalgo, Mexico [17].

It is also possible to find theoretical approaches in which intervention strategies and enrichment of the models are defined, even by comparing examples located in different countries [18].

These experiences not only focus on restoration actions on heritage buildings. It has been found the analysis of case studies from the mid-20th century, examples of modern architecture, such as the Glass House by Lina Bo Bardi. This experience, as occurs with older buildings, has allowed the development of a work methodology to collect, process and manage building information that could be applied in buildings with similar characteristics [19].

Among the contributions that do not focus on the analysis of a case study, those that analyze the strategies carried out during restoration interventions stand out. It is worth 
highlighting the integration of data collection through photogrammetry and laser scanner with BIM work methodologies. Some authors consider that this integration provides an improvement in heritage management and allows the use and analysis of spatial information by GIS [20], [21]. It is also possible to find critical analysis of the available literature that broaden the spectrum of information management in intervention processes, extending them to the evaluation and diagnosis of existing damages in buildings [22].

\subsection{HBIM and the heritage information management}

BIM has emerged as a very useful tool for the complete information management of a heritage building. In this sense, many investigations have been found focused on case studies in which it is intended that the generated repository can improve the maintenance, conservation and restoration actions of listed buildings. It is possible to find successful actions in buildings such as the Cathedral of Parma (Italy) [23], castles in the Piedmont region (Italy) in which the usefulness of multimedia information for Heritage management is shown [24], the Wang Stave Church in Karpcz (Poland), which demonstrates the effectiveness of document management through HBIM platforms in terms of the spatial documentation of the building [25] or the Cartuja de Jerez [26].

3D models created from point clouds surveys and their integration into HBIM modeling platforms is the first action carried out in most of the analyzed research [10] and always attending to the information management of a specific case study [27]-[29].

There are research projects in which among their conclusions it is possible to find that the $3 \mathrm{D}$ model is the concept that allows associating the building information management with the heritage use [30], [31]. These digital surveys are on many occasions enriched with parametric objects, introducing artistic, historical and conservation properties, allowing their exchange with other agents through open formats [32]. It is also possible to find experiences that relate the physical with the virtual by developing Digital Twin techniques for the interpretation of heritage [33].

The generated repositories can be used for other activities related to heritage management such as its use from the cultural point of view and the evaluation of the influence of visitors on heritage conservation [34]. It is very important to have models that, in addition to collecting the geometric characteristics of the building, allow different layers of information about the building state of conservation, the performed interventions and historical periods in which they have been carried out. In addition, it has been found interesting the possibility of integrating all the available information into navigable visual environments. This virtual representation makes any restoration project, preventive conservation, management or dissemination of a cultural asset become a virtual model-mock-up that allows its visit without the need to be in the building [35].

Furthermore, these 3D surveys allow obtaining crucial information to undertake maintenance and restoration works, providing information that cannot be obtained by means of $2 \mathrm{D}$ images [36]. It is worth mentioning the development of research that allows the management of these repositories that are characterized by their large size and offer limitations regarding the hardware to be used [37]. At the same time, it is the interest of some researchers to develop standards that allow better interoperability in many cases related to OpenBIM [38]. In addition, limitations are also identified in the management and exchange of information, developing applications that optimize access to existing documentation by the agents involved at each moment of the useful life of the building [39]. The evaluation of digital repositories that collect information on heritage buildings in a given place is also the 
object of research by some authors, in which strategies are also defined for the development of HBIM platforms [40].

\subsection{HBIM and life cycle analysis}

The life cycle assessment applied to heritage buildings has been the subject of debate due to the impact that the actions necessary to improve the buildings performance may have on protected elements [41], [42]. It is agreed the need of updating this type of buildings as any functional improvement has both social and environmental repercussions [43]. However, the need for the development of specific strategies for life cycle analysis applied to heritage building has been demonstrated in order to make the best decision in the restoration process [44]-[46]. In this sense, the evaluation of strategies to improve the maintenance of this type of buildings are developing new strategies to improve, among other areas, the sustainability of the building [47].

The tools that are integrated into the BIM platforms have allowed a better analysis of the building in the different stages of the architectural project, providing support to the specialists involved in the decision-making process [48]. The use of tools from the BIM environment for the analysis of the life cycle of buildings has also reached heritage buildings. The development of strategies based on HBIM has shown that the integration of geometric and historical data with environmental considerations supports broader issues related to risk management during the maintenance of historic buildings in the context of climate change [49].

The 3D surveys necessary for the generation of the HBIM models have been shown to be a very interesting tool in the process of a global renovation of the building, although the limitations in the libraries limit the data collection. The need for the development of noninvasive data collection has been positively demonstrated with the aim of improving the intervention on listed buildings, especially at the time of improving their energy consumption [50].

\subsection{HBIM and preventive conservation}

The development of strategies for the heritage conservation through PC plans is under research by the scientific community and the digitization and the generation of virtual repositories, under the HBIM environment, begin to be incorporated [51].

The repositories that are generated become the center of all the information related to the heritage building, which can be consulted in an intelligent way and can be used for the building investigation, conservation, management and administration [8], [52]. However, three main issues must be addressed: lack of standardization, insufficient interoperability, and inherent complexity of information. Balancing the geometric and non-geometric characteristics of the model, such as the level of detail precision and the amount of information linked, it is essential for the methodology to be cost-effective and therefore more attractive to end users [38]. It is possible to find experiences in which, through automation and the use of databases, responses to situations found in this type of building are automated [53].

There are experiences in which, based on case studies, protocols have been developed for the maintenance of heritage buildings based on historical documentation, evaluation of the state of conservation, planning of future actions, maintenance and cultural diffusion [54], [55]. As previously described, many of these PC plans are designed based on the integration of information and interoperability. Subsequently they are validated on a case study so that 
their suitability or need for improvement can be evaluated [52], [56]. On other occasions, HBIM repositories are used to help in the decision-making process by defining hierarchies in the information levels that allow organizing the importance of deterioration and favoring the establishment of priorities [57].

However, there are investigations that, aware of the limitations that a 3D repository can have for preventive conservation, design databases which are related to the repository to allow better management of the building by all types of stakeholders. These tools are tested in case studies of the importance of the Cathedral of Parma or the Ducal Palace of Mantua (Italy) [58]. It is also possible to find research projects focused on the development of strategies and guidelines for the development of PC plans based on HBIM [59].

\section{DISCUSSION OF RESULTS}

The analysis of the references found has allowed its organization into four large groups, although it is possible to obtain the following general conclusions (Fig. 5).

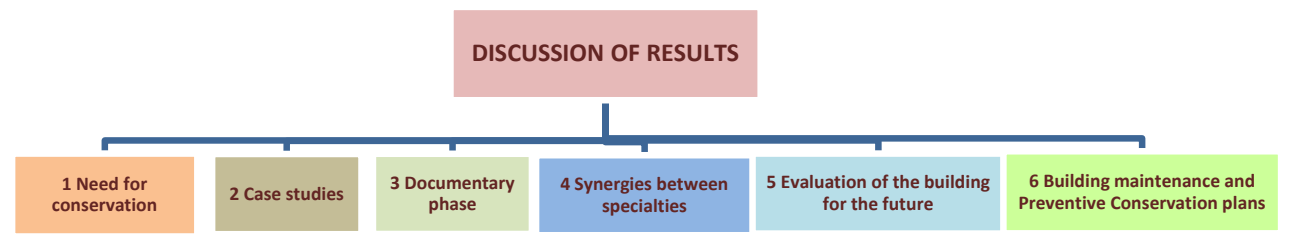

Figure 5: Outline of the discussion of results.

\subsection{Need for conservation}

All the obtained contributions coincide in affirming the need to preserve heritage, treating it as a social value that can only improve societies in which they are located. This situation justifies the development of present and future actions that must focus on the maintenance of this type of buildings over time, allowing access to information by different stakeholders throughout their useful life.

\subsection{Case studies}

There are very few examples that show strategies for the development of interventions in heritage buildings based on HBIM strategies that are the consequence or product of mature processes resulting from previous research. Most contributions are based on case studies and are a first approach to the problem, not allowing to establish a trajectory in the research process. In many cases we speak of very recent contributions in which the short trajectory has not allowed to verify the outcomes beyond the process of restoration of the building. It is worth noting the existence of experiences applied in buildings with architectural value that are not necessarily historical.

\subsection{Documentary phase}

Practically all the contributions have their origin in the preparation of a 3D model that collects the geometric characteristics of the building. In many cases, this is basically the work carried out. The enrichment of the model with other layers of information is proposed as options, announcing its usefulness for other tasks. It is worth noting the existence of experiences 
dedicated to facilitating the management of the information collected in the model through platforms and through the use of free software that can guarantee sustained accessibility over time.

\subsection{Synergies between specialties}

The analysis of the examples found mostly highlights the potential that HBIM has for the collaborative and multidisciplinary development of repositories in which all the information regarding the building under study is collected. In some cases, experiences are demonstrated, although in many cases they are limited to the preparation of the 3D survey and the development of restoration work.

\subsection{Evaluation of the building in the future}

Among the actions that are considered in the previous paragraph it can be found the life cycle analysis applied to the buildings under study. It should be noted that although there is a lot of literature that relates BIM with LCA, it is still not possible to find many experiences applied to buildings with historical values. On the other hand, it is possible to find studies that evaluate the suitability of the HBIM digital repositories generated in the decision-making process. This task is critical, especially in the early stages of the development of the project, since it can condition the viability of the actions that can affect the architectural values that define a listed building.

\subsection{Building maintenance and preventive conservation plans}

As it was above mentioned, most of the literature found focuses on the design of experiences and their validation on case studies. Only a few examples have been found in which the research has focused on the design of a PC plan based on an HBIM repository but which ultimately requires validation. This situation shows the lack of maturity of the discipline and the need for time so that these plans can be developed over time.

\section{CONCLUSIONS}

The analysis of the obtained results in the research shows the interest of a part of the scientific community to improve the intervention processes in heritage buildings and the design of procedures that guarantee their conservation over time. In this sense, the positive synergies between HBIM and the different disciplines that can act during the useful life of these buildings are confirmed. The generation of information repositories with different layers is understood as an opportunity that guarantees a multidisciplinary approach but that is encountering limitations in terms of how to manage them.

The absence of long-term research confirms the novelty of the research field and the need for new proposals that can confirm or modify those already carried out. In this sense, it is worth highlighting the need to generate proposals for Preventive Conservation plans that can integrate different disciplines and that take advantage of the advances in the digitization of construction provided by the tools of the HBIM environment.

\section{ACKNOWLEDGEMENTS}

This work is part of the first results of the research project entitled "Analysis and Development of the integration of BHIM in GIS for the creation of a tourist planning protocol of the cultural heritage of a destination (HBIMSIG-TOURISM)" granted by the Ministry of 
Research of Spain under the 2020 call for R\&D\&I Projects oriented to the Challenges of the Society with the reference PID2020-119088RB-I00.

\section{REFERENCES}

[1] Muñoz Cosme, A., Arquitectura y Memoria. El Patrimonio Arquitectónico y La Ley de Memoria Histórica. Patrim. Cult. España, 1, 2009.

[2] Chapman, E.H. \& Lynch, K., The image of the city. J. Aesthet. Art Crit., 21(1), 1962. https://doi.org/10.2307/427643.

[3] Hajer, M. \& Reijndorp, A., In Search of New Public Domain, 2001.

[4] Gehl, J., Life Between Buildings: Using Public Space, Danish Architectural Press: Copenhagen, 1971.

[5] de Guichen, G., Conservación Preventiva:¿en Qué Punto Nos Encontramos En 2013? Conservación preventiva: revisión de una disciplina, Patrimonio Cultural de España, pp 17-19, 2013.

[6] Gómez, M. \& de Tapol, B., Medio Siglo de Conservación Preventiva. Entrevista a Gaël de Guichen. Entrevista Realizada Por El Comité Científico Técnico Del GEIIC (Marisa Gómez y Benoît de Tapol) En Agosto de 2009. Ge-conservación, pp. 35-44, 2009.

[7] Antonio Herráez, J., Durán, D. \& García Martínez, E., Planes Nacionales Conservacion Preventiva, 2017.

[8] Besana, D., Cultural heritage design: Theories and methods for the project complexity management. EGE-Expresión Gráfica en la Edif., 11, p. 31, 2019.

https://doi.org/10.4995/ege.2019.12864.

[9] García Hernández, M. \& De la Calle Vaquero, M., Geographic research of tourism in Spain. An. Geogr. la Univ. Complut., 24, pp. 257-327, 2004.

[10] Almagro, A., Medio Siglo Documentando El Patrimonio Arquitectónico Con Fotogrametría. EGE Rev. Expresión Gráfica en la Edif., 2019.

[11] Martín Talaverano, R.., Cámara Muñoz, L. \& Murillo Fragero, J.I., Análisis Integrado de Construcciones Históricas: Secuencia Estratigráfica y Diagnóstico Patológico. Aplicación En La Iglesia de Santa Clara (Córdoba). Arqueol. la Arquit., 15, p. 67, 2018. https://doi.org/10.3989/arq.arqt.2018.001.

[12] Galiano-Garrigós, A., González-Avilés, Á., Rizo-Maestre, C. \& Andújar-Montoya, M., Energy efficiency and economic viability as decision factors in the rehabilitation of historic buildings. Sustainability, 2019. https://doi.org/10.3390/su11184946.

[13] Arayici, Y., Counsell, J., Mahdjoubi, L., Hawas, S. \& Dewidar, K., Heritage Building Information Modelling, Routledge, 2017.

[14] Oreni, D., Brumana, R., Della Torre, S., Banfi, F., Barazzetti, L. \& Previtali, M., Survey turned into HBIM: The restoration and the work involved concerning the Basilica Di Collemaggio after the earthquake (L'Aquila). ISPRS Ann. Photogramm. Remote Sens. Spat. Inf. Sci., 2(5), pp. 267-273, 2014. https://doi.org/10.5194/isprsannals-II-5-267-2014.

[15] Brumana, R., Della Torre, S., Previtali, M., Barazzetti, L., Cantini, L., Oreni, D. \& Banfi, F., Generative HBIM modelling to embody complexity (LOD, LOG, LOA, LOI): Surveying, preservation, site intervention - The Basilica Di Collemaggio L'Aquila). Appl. Geomatics, 10(4), 5pp. 45-567, 2018. https://doi.org/10.1007/s12518-018-0233-3.

[16] Nieto, J.E., Moyano, J.J., Rico Delgado, F. \& Antón García, D., Management of built heritage via HBIM project: A case of study of flooring and tiling. Virtual Archaeol. Rev., 7(14), p. 1, 2016. https://doi.org/10.4995/var.2016.4349. 
[17] Mandujano Rodríguez, M.G., Integration of historic building information modeling and valuation approaches for managing cultural heritage sites. 27th Annu. Conf. Int. Gr. Lean Constr. IGLC 2019, pp. 1433-1444, 2019. https://doi.org/10.24928/2019/0253.

[18] Moreira, A., Quattrini, R., Maggiolo, G. \& Mammoli, R., HBIM methodology as a bridge between Italy and Argentina. Int. Arch. Photogramm. Remote Sens. Spat. Inf. Sci.: ISPRS Arch., 42(2), pp. 715-722, 2018. https://doi.org/10.5194/isprs-archives-XLII-2-715-2018.

[19] Cuperschmid, A.R.M., Fabricio, M.M. \& Franco, J.C., HBIM development of a Brazilian modern architecture icon: Glass house by Lina Bo Bardi. Heritage, 2(3), pp. 1927-1940, 2019. https://doi.org/10.3390/heritage2030117.

[20] Yang, X., Grussenmeyer, P., Koehl, M., Macher, H., Murtiyoso, A. \& Landes, T., Review of built heritage modelling: Integration of HBIM and other information techniques. J. Cult. Herit., 46, pp. 350-360, 2020. https://doi.org/10.1016/j.culher.2020.05.008.

[21] Ferreira-Lopes, P. \& Pinto-Puerto, F., GIS and graph models for social, temporal and spatial digital analysis in heritage: The case study of ancient kingdom of Seville late gothic production. Digit. Appl. Archaeol. Cult. Herit., 9, pp. 1-14, 2018.

https://doi.org/10.1016/j.daach.2018.e00074.

[22] Bruno, S., De Fino, M. \& Fatiguso, F., Historic building information modelling: Performance assessment for diagnosis-aided information modelling and management. Autom. Constr., 86, pp. 256-276, 2018. https://doi.org/10.1016/j.autcon.2017.11.009.

[23] Bruno, N. \& Roncella, R., A restoration oriented HBIM system for cultural heritage documentation: The case study of Parma cathedral. Int. Arch. Photogramm. Remote Sens. Spat. Inf. Sci.: ISPRS Arch., 42(2), pp. 171-178, 2018. https://doi.org/10.5194/isprs-archives-XLII-2-171-2018.

[24] Osello, A., Lucibello, G. \& Morgagni, F., HBIM and virtual tools: A new chance to preserve architectural heritage. Buildings, 8(1), pp. 1-12, 2018.

https://doi.org/10.3390/buildings8010012.

[25] Sztwiertnia, D., Ochałek, A., Tama, A. \& Lewińska, P., HBIM (heritage building information model) of the Wang Stave Church in Karpacz: Case study. Int. J. Archit. Herit., 15(5), pp. 713-727, 2021. https://doi.org/10.1080/15583058.2019.1645238.

[26] Castellano-Román, M. \& Pinto-Puerto, F., Dimensions and levels of knowledge in heritage building information modelling, HBIM: The model of the charterhouse of Jerez (Cádiz, Spain). Digit. Appl. Archaeol. Cult. Herit., 14, 2019. https://doi.org/10.1016/j.daach.2019.e00110.

[27] Chiabrando, F., Sammartano, G. \& Spanò, A., Historical buildings models and their handling via 3D survey: From points clouds to user-oriented HBIM. Int. Arch. Photogramm. Remote Sens. Spat. Inf. Sci.: ISPRS Arch., 41, pp. 633-640, 2016. https://doi.org/10.5194/isprsarchives-XLI-B5-633-2016.

[28] López, F.J., Lerones, P.M., Llamas, J., Gómez-Garcia-Bermejo, J. \& Zalama, E., Linking HBIM graphical and semantic information through the Getty AAT: Practical application to the Castle of Torrelobatón. IOP Conf. Ser. Mater. Sci. Eng., 364(1), 2018. https://doi.org/10.1088/1757-899X/364/1/012100.

[29] Chiabrando, F., Lo Turco, M. \& Rinaudo, F., Modeling the decay in an HBIM starting from 3D point clouds: A followed approach for cultural heritage knowledge. Int. Arch. Photogramm. Remote Sens. Spat. Inf. Sci.: ISPRS Arch., 42(2W5), pp. 605-612, 2017. https://doi.org/10.5194/isprs-archives-XLII-2-W5-605-2017. 
[30] Bulgarelli-Bolaños, J.P., Hernández-Salazar, I. \& Pinto-Puerto, F., Evolución de La Producción Científica Sobre Los Conceptos HBIM y Modelado 3D En La Gestión de Obras Patrimoniales. Rev. Tecnol. en Marcha, pp. 89-101, 2020.

https://doi.org/10.18845/tm.v33i8.5512.

[31] Brumana, R., Oreni, D., Raimondi, A., Georgopoulos, A. \& Angeliki, B., From survey to HBIM for documentation, dissemination and management of built heritage. 2013 Digit. Herit. Int. Congr., pp. 497-504, 2013.

[32] Nieto-Julián, J.E., Lara, L. \& Moyano, J., Implementation of a teamwork-HBIM for the management and sustainability of architectural heritage. Sustain., 13(4), pp. 1-26, 2021. https://doi.org/10.3390/su13042161.

[33] Dezen-Kempter, E., Mezencio, D.L., Miranda, E.D.M., de Sãi, D.P. \& Dias, U., Towards a digital twin for heritage interpretation. RE Anthr. Des. Age Humans: Proc. 25th Int. Conf. Comput. Archit. Des. Res. Asia, CAADRIA 2020, 2, pp. 183-191, 2020.

[34] Salvador-García, E., Valldecabres, J.L.G. \& Blasco, M.J.V., Integrating HBIM models in the management of the public use of heritage buildings. Can. J. Civ. Eng., 47(2), pp. 228-235, 2020. https://doi.org/10.1139/cjce-2018-0338.

[35] Armisén, A., HBIM Successful Case Study, 2018.

[36] Ermenyi, T., Enegbuma, W.I, Isaacs, N. \& Potangaroa, R., Building information modelling workflow for heritage maintenance. Proc. Int. Conf. Archit. Sci. Assoc., pp. 220-225, 2020.

[37] Rechichi, F., Mandelli, A., Achille, C. \& Fassi, F., Sharing high-resolution models and information on web: The web module of Bim3dsg system. Int. Arch. Photogramm. Remote Sens. Spat. Inf. Sci.: ISPRS Arch., 41(July), pp. 703-710, 2016. https://doi.org/10.5194/isprsarchives-XLI-B5-703-2016.

[38] Barontini, A., Alarcon, C., Sousa, H.S., Oliveira, D.V., Masciotta, M.G. \& Azenha, M., Development and demonstration of an HBIM framework for the preventive conservation of cultural heritage. Int. J. Archit. Herit., 2021. https://doi.org/10.1080/15583058.2021.1894502.

[39] Quattrini, R., Pierdicca, R., Morbidoni, C. \& Malinverni, E.S., Conservation-oriented HBIM. The Bimexplorer web tool. Int. Arch. Photogramm. Remote Sens. Spat. Inf. Sci.: ISPRS Arch., 42(5W1), pp. 275-281, 2017. https://doi.org/10.5194/isprsArchives-XLII-5-W1-275-2017.

[40] Fadli, F. \& AlSaeed, M., Digitizing vanishing architectural heritage: The design and development of Qatar historic buildings information modeling [Q-HBIM] platform. Sustain., 11(9), 2019. https://doi.org/10.3390/su11092501.

[41] Fouseki, K. \& Cassar, M., Energy efficiency in heritage buildings: Future challenges and research needs. Hist. Environ. Policy Pract., 5(2), pp. 95-100, 2014. https://doi.org/10.1179/1756750514Z.00000000058.

[42] Cabeza, L.F., de Gracia, A. \& Pisello, A.L., Integration of renewable technologies in historical and heritage buildings: A review. Energy Build., 177, pp. 96-111, 2018. https://doi.org/10.1016/j.enbuild.2018.07.058.

[43] Berg, F. \& Fuglseth, M., Life cycle assessment and historic buildings: Energyefficiency refurbishment versus new construction in Norway. J. Archit. Conserv., 24(2), pp. 152-167, 2018. https://doi.org/10.1080/13556207.2018.1493664.

[44] Munarim, U. \& Ghisi, E., Environmental feasibility of heritage buildings rehabilitation. Renewable and Sustainable Energy Reviews, 2016. https://doi.org/10.1016/j.rser.2015.12.334. 
[45] Angrisano, M., Fabbrocino, F., Iodice, P. \& Girard, L.F., The evaluation of historic building energy retrofit projects through the life cycle assessment. Appl. Sci., 11(15), 2021. https://doi.org/10.3390/app11157145.

[46] Atmaca, N., Atmaca, A. \& Özçetin, A.İ., The impacts of restoration and reconstruction of a heritage building on life cycle energy consumption and related carbon dioxide emissions. Energy Build., 253, 111507, 2021.

https://doi.org/10.1016/J.ENBUILD.2021.111507.

[47] Adegoriola, M.I., Lai, J.H.K., Chan, E.H. \& Amos, D., Heritage building maintenance management (HBMM): A bibliometric-qualitative analysis of literature. J. Build. Eng., 42, 102416, 2021. https://doi.org/10.1016/j.jobe.2021.102416.

[48] Güngör, İ. \& Benli, Y.N., Evaluation of building information modelling (BIM) based life cycle assessment (LCA). ATI, Archit. Innov. Technol., 2020.

[49] Prizeman, O., Pezzica, C., Taher, A. \& Boughanmi, M., Networking historic environmental standards to address modern challenges for sustainable conservation in HBIM. Appl. Sci., 10(4), 2020. https://doi.org/10.3390/app10041283.

[50] Prizeman, O.E.C., HBIM and matching techniques: Considerations for late nineteenthand early twentieth-century buildings. J. Archit. Conserv., 21(3), pp. 145-159, 2015. https://doi.org/10.1080/13556207.2016.1139852.

[51] Khodeir, L.M., Aly, D. \& Tarek, S., Integrating HBIM (heritage building information modeling) tools in the application of sustainable retrofitting of heritage buildings in Egypt. Procedia Environ. Sci., 34, pp. 258-270, 2016. https://doi.org/10.1016/j.proenv.2016.04.024.

[52] Mora, R., Sánchez-Aparicio, L.J., Maté-González, M.Á., García-Álvarez, J., SánchezAparicio, M. \& González-Aguilera, D., An historical building information modelling approach for the preventive conservation of historical constructions: Application to the historical library of Salamanca. Autom. Constr., 121, 2021.

https://doi.org/10.1016/j.autcon.2020.103449.

[53] La Russa, F.M. \& Santagati, C., An AI-based DSS for preventive conservation of museum collections in historic buildings. J. Archaeol. Sci. Reports, 35, 102735, 2021. https://doi.org/10.1016/j.jasrep.2020.102735.

[54] Jordan-Palomar, I., Tzortzopoulos, P., García-Valldecabres, J. \& Pellicer, E., Protocol to manage heritage-building interventions using heritage building information modelling (HBIM). Sustain., 10(4), 2018. https://doi.org/10.3390/su10040908.

[55] Angulo-Fornos, R. \& Castellano-Román, M., HBIM as support of preventive conservation actions in heritage architecture. Experience of the Renaissance quadrant facade of the cathedral of Seville. Appl. Sci., 10(7), 2020. https://doi.org/10.3390/app10072428.

[56] Fonnet, A., Alves, N., Sousa, N., Guevara, M. \& Magalhães, L., Heritage BIM integration with mixed reality for building preventive maintenance. EPCGI 2017: 24th Encontro Port. Comput. Graf. e Interacao, pp. 1-7, 2017. https://doi.org/10.1109/EPCGI.2017.8124304.

[57] Acampa, G. \& Grasso, M., Heritage evaluation: restoration plan through HBIM and MCDA. IOP Conf. Ser. Mater. Sci. Eng., 949(1), 2020. https://doi.org/10.1088/1757-899X/949/1/012061.

[58] Bruno, N. \& Roncella, R., HBIM for conservation: A new proposal for information modeling. Remote Sens., 11(15), 2019. https://doi.org/10.3390/rs11151751.

[59] Talon, A., Cauvin, C. \& Chateauneuf, A., State of the art of HBIM to develop the HBIM of the heritagecare project. Int. J. 3-D Inf. Model., 6(3), pp. 33-43, 2018. https://doi.org/10.4018/ij3dim.2017070103. 